\title{
Impact of a Cross-Institutional Assessment Designed to Shape Future IT Professionals
}

\author{
Grace Tan \& Anne Venables \\ Victoria University, Melbourne, Victoria, Australia \\ grace.tan@vu.edu.au anne.venables@live.vu.edu.au
}

\begin{abstract}
IT graduates need a suite of technical competencies and soft skills married with an understanding of the social and business contexts of the systems that they build. To instill in students an awareness of current IT industry practice coupled with the broader impact of their discipline in society, academics from Victoria University and Federation University initiated an across-institutional collaboration. The initiative resulted in a common formative assessment task undertaken by teams of students enrolled in each institution's professional development units.

An initial survey of students was undertaken prior to the assessment task. The survey queried students' perceptions of a broad range of professional attitudes and skill sets needed by IT professionals when compared to non-skilled workers. Upon the completion of the assessment task, students were surveyed again as to their perceptions of the importance of personal skills, technical competencies, professional and team working skills, workplace knowledge, and cultural awareness for their future professional lives. Comparisons of both surveys' results revealed that the cohort had a greater appreciation of technical abilities and team-working skills post the assessment task.
\end{abstract}

Keywords: information technology (IT), across-institution assessment, professional skills development, survey

\section{Introduction}

Australian national threshold learning outcomes for the Information Technology (IT) discipline were established after extensive consultation with academics, industry professionals, accreditation bodies, students, and graduates; the resulting Engineering and ICT Learning and Teaching Academic Standards Statement was published in December 2010 (Australian Learning and Teaching Council, 2010). The five learning outcome areas identified are (1) problem-solving and design, (2) abstraction and modeling, (3) needs, context and systems, (4) coordination and com-

Material published as part of this publication, either on-line or in print, is copyrighted by the Informing Science Institute. Permission to make digital or paper copy of part or all of these works for personal or classroom use is granted without fee provided that the copies are not made or distributed for profit or commercial advantage AND that copies 1) bear this notice in full and 2) give the full citation on the first page. It is permissible to abstract these works so long as credit is given. To copy in all other cases or to republish or to post on a server or to redistribute to lists requires specific permission and payment of a fee. Contact Publisher@InformingScience.org to request redistribution permission. munication, and (5) self-management, and they are to be used by Australian academics to align their undergraduate IT curricula. Typically, IT curricula cover the first two learning outcomes as they focus on the large repertoire of technical skills needed by graduates to cope in an increasingly connected world. The greater challenge for educators is to realistically tackle the remaining three learning outcomes, in that, it is 
more difficult to ensure opportunities for students to acquire and develop the necessary teamwork, leadership, and people skills together with an appreciation of the social, cultural, legislative, environmental, and business contexts of the systems that they build (Aasheim, Li, \& Williams, 2009; Zhang, 2012). Some time ago, academics from Victoria University and Federation University came together to discuss this challenge and formulate a curriculum response that resulted in an across-institutional teaching collaboration.

There were two main drives for the teaching collaboration, one being the need to broaden students' understanding of current professional IT business practices with an appreciation of the set of personal skills and technical competencies needed in their future careers (Kamoun \& Selim, 2007). The second drive was the desire to ensure quality assurance in our respective undergraduate IT programs. A suitable professional development unit at each institution was selected to enable students to practice professional skills, including soft skills, technical competencies, team work, and focus on ethical and societal issues in IT.

\section{The Cross-institutional Assessment}

Academics from both institutions recognized the power of assessment to motivate students and drive learning outcomes, particularly formative assessments that encourage students to learn through the process of doing (Black \& William, 2009; Boud \& Falchikov, 2007; William \& Thompson, 2007). A formative assessment task drawing upon common topics in the two professional development units was coauthored by the teaching academics at both institutions. The task was contextualized around real-life IT business practice and professional behaviors, particularly in response to ethical dilemmas, security challenges, and threats to privacy. Since, students have few opportunities to network with IT practitioners, the assessment incorporated a 'novice meets expert' experience where teams of students would interview an IT professional with a leadership role. Importantly, opportunities to improve students' interpersonal and communication skills and self-management capabilities were further extended through the added dimension of working with students from a partner institution. The rationale for the collaboration and assessment details are published in Venables, Tan, \& Pradhan (2014). The project commenced with an extensive review of the research literature to uncover similar efforts within IT education, yet to the best of our knowledge the use of a common assessment task across two institutions is entirely novel.

The first task for students completing the cross-institutional assessment was to assign themselves to a team of four members, comprising two students from each institution. Once team memberships were decided, introductions needed to be made between group members; this posed a physical challenge as the two participating universities are some 100 kilometers apart. Together, team members needed to identify an IT business manager who would be willing to be interviewed and to make contact with him or her. An appropriate set of interview questions were to be designed and submitted for consideration and approval by the supervising academics. The questions were to be centered on IT professional practices that were related to the topics of security challenges, privacy threats, ethical dilemmas, project management, and employee relations. Academics hoped that their students would realize the importance of various technical competencies, personal and team-working skills, workplace knowledge, and cultural considerations through interviewing an IT practitioner for their workplace insights.

Subsequently, students negotiated an interview time at which all team members would participate. At the interview an audio recording needed to be made. After the interview the team would collate a written report of the interview experience and present their group findings of the topics discussed. These post-interview activities were designed to give students opportunities to discuss and reflect on their views and understandings of the importance of professional issues for IT businesses. 
There have been two iterations of the common assessment task in the offerings of both institutes' professional development units involving a total of nearly 150 undergraduates. Over 30 interviews of ICT managers were conducted by student teams on the topic of professional behaviors and practice. For each running, a joint University function was arranged to enable cross-institute teams to present their understandings derived from their interviews. The team presentations and associated reports were assessed by academics from both universities.

\section{The Surveys}

In the first implementation of the cross-institutional assessment, anecdotal feedback concerning the experience from participants was very positive. For the second iteration, students were asked to complete pre- and post- assessment task surveys, being near identical in their questions. For conducting the surveys, ethics clearance was obtained. Student participation was voluntary for which respondents generated their own unique identifier in order that they remain anonymous to survey collators; the unique identifier allowed pairing of pre- and post- survey responses. In total, 31 survey pairs were collected only from Victoria University students as administrative problems precluded a timely collection of responses from Federation University participants.

Together, the surveys were designed to quantify shifts in students' perceptions of the skill set needed for their future professional practice. Each survey comprises 10 background information questions and 60 statements, which were designed to query student attitudes as to the importance, or otherwise, of a range of personal and team working skills, workplace knowledge, and various technical and cultural competencies. To check for response consistency, some unrelated skill sets were included (such as ability to play a musical instrument) while several statements were deliberately repeated. The most significant survey questions are presented in the Survey Results section following. Statement responses were scored using a Likert scale of 'not very important, not important, unsure of importance, a little important, and very important'. The final component of the surveys consists of a small set of short answer questions. In common, the first four questions queried student attitudes to working with strangers in their teams. Students were asked to explain their strategies for self-management in meeting competing deadlines and those needed for conflict resolution that may arise in team work. The surveys themselves may be reconstructed through the collation of all tables reported here and for brevity they have not been added to the paper.

Additionally the pre-survey makes a comparison to the attributes needed by IT workers versus non-skilled IT workers. As reported below, many students had work experiences in hospitality and counter-service so the surveys asked them to make comparisons to the skills needed by a counter staff member in a fast food business. Additionally, the post survey asked for student reflections on what they had learnt about professional skills from the 'novice meets expert' experience.

\section{Survey Results}

Responses to the background information questions revealed that the student cohort is culturally diverse, in that more than half were born overseas, with the large majority speaking and having studied in a language other than English. It was revealed that most respondents have had paid employment whilst completing their studies (inclusive of casual, part-time, and full-time work) and more than half of these needed to work throughout the teaching semester. Yet despite, the extensive reported work experiences, only $10 \%$ of students were currently working in an ITrelated position whilst the majority worked in the hospitality industry to support themselves. A small percentage $(10 \%)$ of students had needed to travel overseas at some stage for work.

Following are the collated student responses to both surveys. The questions have been aggregated into sets reflecting student perceptions of personal skills, workplace knowledge, technical compe- 
tencies, team skills, cultural competencies, and professional life for the IT profession and a nonIT workplace. Each set is reported in its own table. Each table shows the percentages of respondents who say the particular skill set is important or very important for a person working as counter staff member in a fast food business in comparison to an IT professional in a large corporation. Note, in all tables the percentages have been reported to the nearest $5 \%$, and comparisons of less than or equal to $5 \%$ are considered to essentially the same result as they represent only one or two individual responses being different for the following descriptions.

As seen in Table 1, several questions related to a range of personal skills, such as showing initiative, being able to work autonomously, and to work under pressure. According to the preassessment survey responses, several skills were seen as important to students regardless of the workplace. For instance, being punctual (Q11), clear in conversations (Q18, Q21, and Q70), having good time management skills (Q12), and assuming personal responsibilities (Q28 and Q61) are seen to be of equal importance irrespective of the work environment. Other personal skills were more clearly identified with IT professionals over non-IT roles; these were being creative and showing initiative (Q13, Q23 and Q 39), the ability to work under pressure, staying on task and meeting deadlines (Q19, Q22 and Q40), and the ability to learn new things (Q41).

Table 1: Survey responses relating to personal skills prior and post the cross-institutional assessment

\begin{tabular}{|l|l|c|c|c|}
\hline \multicolumn{2}{|l}{} & \multicolumn{3}{c|}{$\begin{array}{c}\text { of respondents who say the skill is im- } \\
\text { portant or very important for }\end{array}$} \\
\cline { 3 - 5 } & $\begin{array}{c}\text { A counter } \\
\text { staff member } \\
\text { in fast food } \\
\text { business }\end{array}$ & $\begin{array}{c}\text { An IT professional in a large } \\
\text { corporation }\end{array}$ \\
\hline Q & Survey & $\begin{array}{c}\text { Pre- } \\
\text { assessment }\end{array}$ & $\begin{array}{c}\text { Pre- } \\
\text { assessment }\end{array}$ & $\begin{array}{c}\text { Post- } \\
\text { assessment }\end{array}$ \\
\hline Q11 & Being punctual and on time to work & 80 & 80 & 80 \\
\hline Q12 & Having good time management skills & 70 & 70 & 60 \\
\hline Q13 & Being imaginative & 70 & 90 & 90 \\
\hline Q18 & Understanding what people say to me & 70 & 75 & 60 \\
\hline Q19 & Being able to work under pressure & 40 & 60 & 90 \\
\hline Q21 & Being able to give others clear instructions & 70 & 70 & 60 \\
\hline Q22 & Being able to work to deadlines & 60 & 75 & 90 \\
\hline Q23 & Being creative & 40 & 60 & 75 \\
\hline Q28 & Knowing the difference between right \& wrong & 70 & 75 & 90 \\
\hline Q39 & Showing initiative & 55 & 75 & 80 \\
\hline Q40 & Staying focused on the task & 70 & 80 & 85 \\
\hline Q41 & Having the ability to learn new things & 70 & 80 & 85 \\
\hline Q61 & Taking responsibility for you own actions & 75 & 80 & 80 \\
\hline Q70 & Being able to follow instructions & 75 & 75 & 85 \\
\hline
\end{tabular}

Pre- and post- assessment responses of Table 1 help indicate the influence of the 'novice meets expert' experience on student understanding of personal skills. The results show a significant shift in recognition of the importance of being able to work under pressure and to deadlines (Q19 and 
Q22), being creative (Q23), and being able to follow instructions (Q70). All other response remained relatively constant with two minor exceptions, being the possessor of good time management skills (Q12) and being able to give others clear instructions (Q21), which students did not perceive to the same degree of importance after completing the assessment. We have no clue as to why student perceptions changed in this manner, and this would need to be investigated in more detail in future iterations of the assessment instrument.

Various aspects of workplace knowledge abilities are presented in Table 2, where it can be seen that knowing employment conditions (Q32 and Q45) and the organizational structure (Q36 and Q49), understanding privacy and confidentiality (Q56), and recognizing the Occupational Health and Safety issues (Q65) are perceived to be equally important in both workplaces. Students recognized the greater importance of knowing the Acceptable Internet Use Policy and understanding copyright and plagiarism issues for IT professionals.

Table 2: Survey responses relating to workplace knowledge prior and post the cross-institutional assessment

\begin{tabular}{|l|l|c|c|c|}
\hline \multicolumn{2}{|c|}{ Workplace knowledge } & \multicolumn{3}{c|}{$\begin{array}{c}\text { \% of respondents who say the skill is im- } \\
\text { portant or very important for }\end{array}$} \\
\cline { 3 - 5 } & $\begin{array}{c}\text { A counter } \\
\text { staff member } \\
\text { in fast food } \\
\text { business }\end{array}$ & $\begin{array}{c}\text { An IT professional in a large } \\
\text { corporation }\end{array}$ \\
\hline Q & Survey & $\begin{array}{c}\text { Pre- } \\
\text { assessment }\end{array}$ & $\begin{array}{c}\text { Pre- } \\
\text { assessment }\end{array}$ & $\begin{array}{c}\text { Post- } \\
\text { assessment }\end{array}$ \\
\hline $\begin{array}{l}\text { Q32 } \\
\text { Q45 }\end{array}$ & Knowing terms \& conditions of employment & 70 & 75 & 85 \\
\hline Q36 & Knowing the structure of the organization & 65 & 70 & 85 \\
\hline Q56 & Understanding privacy \& confidentiality & 75 & 75 & 80 \\
\hline Q57 & Knowing the Acceptable Internet Use Policy & 50 & 80 & 80 \\
\hline Q60 & Understanding copyright \& plagiarism & 55 & 75 & 80 \\
\hline Q65 & Recognizing Occupational Health \& Safety issues & 75 & 75 & 75 \\
\hline
\end{tabular}

After interviewing a practicing IT professional, students saw the increased importance of the workplace structure and employment conditions as evidenced by larger 'important or very important' response rates to Q32, Q36, Q45, and Q49. Other questions' percentage rates remained relatively consistent prior and post the assessment.

Perhaps not surprisingly, the acquisitions of technical competencies were seen to be far more important for IT professionals than for counter staff, as indicated in Table 3 for all questions asked. The 'important or very important' post-interview responses marginally increased for the following skill: being able to open and close computer programs (Q15), learn new technologies and equipment (Q17), being good at mathematics (Q27), and being able to memorize facts and data (Q30 and Q43) and to understand email etiquette (Q68). A more significant increase in response rate was seen for being able to write a clear and understandable report (Q24) and being proficient in a technical language (Q69). The greatest margin of increase in students' perceptions was in being technically competent (Q34 and Q47). 
Table 3: Survey responses relating to technical competencies prior and post the cross-institutional assessment

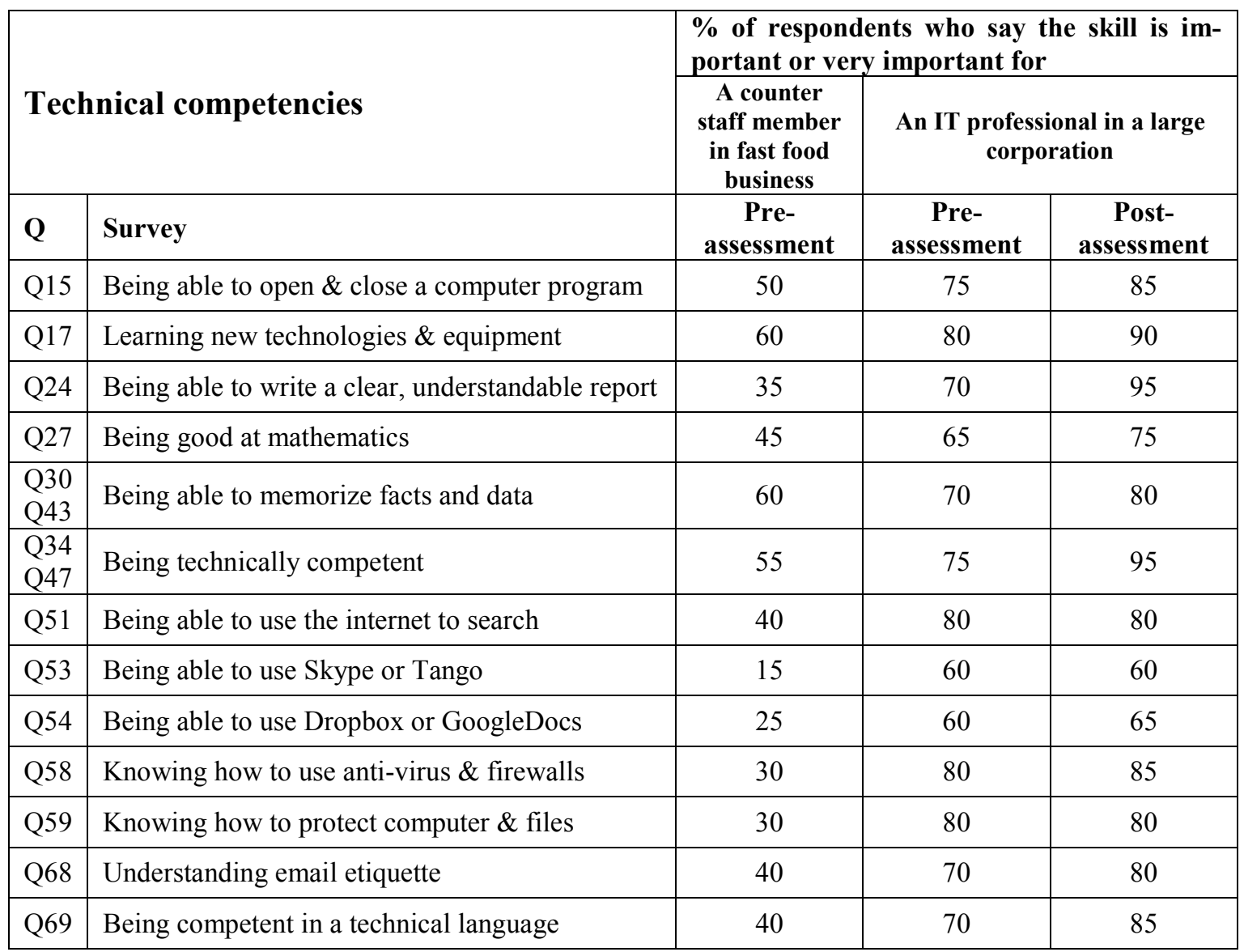

Table 4 collates survey responses to the team skill set of questions. The pre-assessment questions with similar response rates for both workplaces are being able to work with new people (Q33 and Q46), being able to consult with others and get their opinions (Q50), and treating everyone equally (Q63). However, students believe that the following skills are more important in the IT workplace: being a contributing member of a team (Q16), having colleagues rely on them (Q20), being able to give constructive feedback (Q52), working with colleagues and respecting privacy (Q55), and being sympathetic and emphatic (Q64).

Following the assessment task, students' perceptions for several team skills increased considerably in their importance. They were being a contributing member of a team (Q16), being able to work with new people (Q33 and Q46), and being able to consult with others and get opinions (Q50). Smaller but discernable changes in student were noted for the ability to give constructive feedback (Q52) and treating everyone equally (Q63). Most interestingly, there is a drop in the perceived importance of being sympathetic and emphatic (Q64) as a team skill. 
Table 4: Survey responses relating to team skills prior and post the cross-institutional assessment

\begin{tabular}{|l|l|c|c|c|}
\hline \multicolumn{2}{|l}{} \\
\multicolumn{2}{|l}{ Team skills } & $\begin{array}{c}\text { \% of respondents who say the skill is im- } \\
\text { portant or very important for }\end{array}$ \\
\cline { 3 - 5 } & $\begin{array}{c}\text { A counter } \\
\text { staff member } \\
\text { in fast food } \\
\text { business }\end{array}$ & $\begin{array}{c}\text { An IT professional in a large } \\
\text { corporation }\end{array}$ \\
\hline Q & Survey & $\begin{array}{c}\text { Pre- } \\
\text { assessment }\end{array}$ & $\begin{array}{c}\text { Pre- } \\
\text { assessment }\end{array}$ & $\begin{array}{c}\text { Post- } \\
\text { assessment }\end{array}$ \\
\hline Q16 & Being a contributing member of a team & 60 & 70 & 90 \\
\hline Q20 & Having my colleagues being able to rely on me & 50 & 65 & 65 \\
\hline $\begin{array}{l}\text { Q33 } \\
\text { Q46 }\end{array}$ & Being able to work with new people & 70 & 65 & 85 \\
\hline Q50 & Being able to consult with others \& get opinions & 70 & 65 & 85 \\
\hline Q52 & Being able to give constructive feedback & 55 & 70 & 80 \\
\hline Q55 & Working with colleagues \& respecting privacy & 70 & 80 & 80 \\
\hline Q63 & Treating everyone equally & 70 & 70 & 80 \\
\hline Q64 & Being sympathetic \& emphatic & 60 & 75 & 65 \\
\hline
\end{tabular}

Cultural competencies were queried by five different questions. The competencies of being able to work with different cultures (Q26) and the ability to speak a foreign language (Q38) were seen as equally important for IT professionals as others. The ability to talk to strangers (Q29 and Q42) was to be of less importance for IT workers than counter staff, yet the preparedness to travel (Q67) was marginally more important for IT professionals. Subsequent to the assessment, there were significant changes in how students perceived cultural competencies for being able to work with different cultures (Q26) and being able to talk to strangers (Q29 and Q42).

Table 5: Survey responses relating to cultural competencies prior and post the cross-institutional assessment

\begin{tabular}{|l|l|c|c|c|}
\hline \multicolumn{2}{|c|}{} & \multicolumn{2}{c|}{$\begin{array}{c}\% \text { of respondents who say the skill is im- } \\
\text { portant or very important for } \\
\text { A counter } \\
\text { staff member } \\
\text { in fast food } \\
\text { business }\end{array}$} & $\begin{array}{c}\text { An IT professional in a large } \\
\text { corporation }\end{array}$ \\
\hline Q & Survey & $\begin{array}{c}\text { Pre- } \\
\text { assessment }\end{array}$ & $\begin{array}{c}\text { Pre- } \\
\text { assessment }\end{array}$ & $\begin{array}{c}\text { Post- } \\
\text { assessment }\end{array}$ \\
\hline Q26 & Being able to work with different cultures & 65 & 65 & 85 \\
\hline Q29 & Being able to talk to strangers & 70 & 55 & 80 \\
\hline Q42 & Being able to speak a foreign language & 45 & 50 & 50 \\
\hline Q67 & Being prepared to travel & 40 & 50 & 45 \\
\hline
\end{tabular}

Only three questions specifically queried aspects of professional life. In every case, these aspects were judged more important for IT professionals than for other employees. After the "novice meets expert' experience, there were positive shifts in percentage responses. 
Table 6: Survey responses relating to professional life prior and post the cross-institutional assessment

\begin{tabular}{|c|c|c|c|c|}
\hline \multirow{2}{*}{\multicolumn{2}{|c|}{ Professional life }} & \multicolumn{3}{|c|}{$\begin{array}{l}\text { \% of respondents who say the skill is im- } \\
\text { portant or very important for }\end{array}$} \\
\hline & & \multirow{2}{*}{ 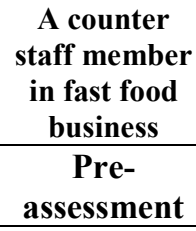 } & \multicolumn{2}{|c|}{$\begin{array}{l}\text { An IT professional in a large } \\
\text { corporation }\end{array}$} \\
\hline $\mathbf{Q}$ & Survey & & $\begin{array}{c}\text { Pre- } \\
\text { assessment }\end{array}$ & $\begin{array}{c}\text { Post- } \\
\text { assessment }\end{array}$ \\
\hline $\begin{array}{l}\text { Q35 } \\
\text { Q48 }\end{array}$ & Being a member of a professional organization & 40 & 50 & 65 \\
\hline Q66 & Planning for career development & 55 & 70 & 80 \\
\hline
\end{tabular}

The first set of short answer questions asked students to estimate the amount of time needed to get to know others when working together on assessments and how they would go about resolving disagreements and managing conflicts. Generally, students offered longer and more realistic estimates of the time needed to get to know assignment partners on their post- assessment surveys. Short answer responses to a question regarding problems in meeting deadlines for competing assessments changed from students preferring to work sequentially on various tasks to the majority realizing that they needed to parallel manage the tasks to meet deadlines.

Pre- and post- survey questions asked students to list the most important professional skills needed for IT professional. Even though a variety of technical, communication, and personal skills were listed in the pre- assessment responses, technical skills were the most numerous; this is in contrast to post- assessment responses where the soft skills predominate.

\section{Discussion}

The assessment task provided a mechanism for students from Victoria and Federation Universities to gain an 'industry-informed' understanding of the importance of professional skills in IT practice and, through an authentic networking experience, the opportunity to practice a suite of teamwork and communication skills. The impact of the assessment task is seen in student responses to a swath of questions designed to test their perceptions of importance of each of the learning outcome areas in the ICT Learning and Teaching Academics Standards Statement, being the technical skills of problem solving and design together with abstraction and modeling, contextual aspects, communication, and personal skills. Mindful of the limitations of the voluntary response rates, it was shown that Victoria University students collectively endorsed the collaborative experience as evidenced in their increased perceptions of the importance of a number of technical, personal and professional attributes as reported in the Results section.

IT curricula have at their core the solid development of technical competencies in their program deliveries (ABET 2012; Australian Computer Society, 2012, 2013). Students recognized the training in these skills as most important for members of the IT profession rather than for others. The impact of the cross-institute assessment experience is shown by almost all respondents $(95 \%)$ noting the importance of being technically competent and appreciating the ability to write a clear and understandable report for IT professionals (Table 3). It seems that the 'novice meets expert' experience has underlined the significance of these competencies together with being proficient in a technical language.

An important aspect of the assessment required that students work in cross-institutional teams in order that they practice personal and communication skills when networking with students from 
their partner institution. To do so, team members were required to overcome the difficulties and logistical problems posed by working with new colleagues. Perhaps not surprisingly, for IT students various technical solutions were devised to overcome communication problems. Interestingly, survey responses to the background question 'do you prefer to work alone' show a shift from $45 \%$ prior to the assessment task to $30 \%$ afterwards. This supports the notion that students collectively endorsed the collaborative experience, in that they saw value in cross-institutional teamwork, despite the inherent logistical hurdles designed into the assessment. This hypothesis is evidenced in Table 1 where noticeable shifts between pre- and post- assessment responses show student recognition of the importance of personal skills of working under pressure and to deadlines, being creative whilst knowing the difference between right and wrong.

Basic good team skills, such as being able to work respectfully with new people and being consultative, are seen as being important irrespective of workplace (Table 4). However, the following skills were seen to have more importance for IT professionals: being a contributing and reliable team member and having the ability to provide constructive feedback respectfully. Huge shifts in comprehending the importance of several team skills are noted in the post assessment responses. Students overwhelming verified the importance of being a consultative and contributing team member whilst working with new people. Other personal skills regarding cultural competencies saw major shift in student perceptions of importance (Table 5). In particular, the ability to talk to strangers and work with different cultures was greatly increased post the assessment task.

It seems that students had an understanding that knowing the workplace policies and issues are very important (Table 2). For IT professionals, they identified the greater importance in the workplace for knowledge of the Acceptable Internet Use Policy and understanding of copyright and plagiarism issues. After conducting their interviews, students showed an increased awareness of the importance of organizational structure and employment conditions for IT professionals. Aspects of professional life of planning a career and being a member of a professional body showed increases in importance after the interview experience (Table 6).

The analysis of survey responses attest to a shift in student perceptions of various personal skills, technical competencies, professional and team working skills, workplace knowledge and cultural awareness, needed in IT practice. Further, the assessment task has been supported by IT industry professionals who volunteered to be interviewed and offer their valuable insights to our students.

A number of lessons have been learnt throughout the two iterations of a cross-institutional assessment. In reality, anticipating academics experienced similar difficulties to those experienced by their students in overcoming barriers of distance and the mechanics of unit scheduling and timetabling constraints. A necessary precursor to such an effort is the absolute need for academic champion at each institute to propel the project and to steer it through the many obstacles. The considerable effort and investment in implementing the cross-institutional assessment has led to improved teaching resources in the IT professional development units at both institutes together with stronger relationships to pave the way for future collaborations. It has been suggested that similar efforts for collaboration and benchmarking across institutions is worthy of consideration in other disciplines.

\section{Acknowledgement}

The development of a cross-institutional assessment task outlined in this article has been supported by an Australian Council of Deans of ICT teaching grant. We wish to thank Mr Sunam Pra-

dhan and Ms Sally Firmin of Federation University (formally University of Ballarat) for their participation in the collaboration. 


\section{References}

Aasheim, C., Li, L., \& Williams, S. (2009). Knowledge and skill requirements for entry-level information technology workers: A comparison of industry and academia. Journal of Information Systems Education, 20(3), 349-356.

ABET. (2012). Criteria for accrediting computing programs. Retrieved 25 November 2014 from http://www.abet.org/uploadedFiles/.../cac-criteria-2013-2014.pdf

Australian Computer Society. (2012). The ICT profession body of knowledge. Retrieved 25 November 2014 from http://www.acs.org.au/_data/assets/pdf file/0007/7792/The-ICT-Profession-Body-ofKnowledge.pdf

Australian Computer Society. (2013). ACS certification guidelines, 2013. Retrieved 25 November 2014 from https://www.acs.org.au/_ data/assets/pdf_file/0004/16762/ACS-CertificationGuidelines 19_March 2013_v2.4.pdf

Australian Learning and Teaching Council. (2010). Engineering and ICT learning and teaching academic standards statement. Retrieved 25 November 2014 from http://www.olt.gov.au/system/.../altc_standards_ENGINEERING_090211.pdf

Black, P., \& William, D. (2009). Developing the theory of formative assessment. Educational Assessment, Evaluation and Accountability, 21, 5-31.

Boud, D., \& Falchikov, N. (Eds.). (2007). Rethinking assessment in higher education: Learning for the longer term. London: Routledge.

Kamoun, F., \& Selim, S. (2007). A framework towards assessing the merits of inviting IT professionals to the classroom. Journal of Information Technology Education, 6, 81-103. Retrieved from http://www.jite.org/documents/Vol6/JITEv6p081-103Kamoun223.pdf

Venables, A., Tan, G., \& Pradhan, S. (2014). A collaborative framework for a cross-institutional assessment to shape future IT professionals. Issues in Informing Science and Information Technology, 11, 215-223. Retrieved from http://iisit.org/Vol11/IISITv11p215-223Venables0451.pdf

Wiliam, D., \& Thompson, M. (2007). Integrating assessment with instruction: What will it take to make it work? In C. A. Dwyer (Ed.), The future of assessment: Shaping teaching and learning (pp. 53-82). Mahwah, NJ: Erlbaum.

Zhang. A. (2012). Peer assessment of soft skills and hard skills. Journal of Information Technology Education, 11, 155-168. Retrieved from http://www.jite.org/documents/Vol11/JITEv11p155168Zhang1119.pdf

\section{Biographies}

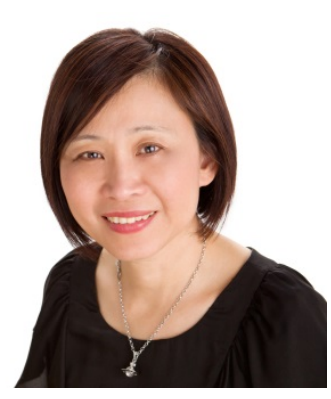

Grace Tan is a senior lecturer in Information Technology at Victoria University, Melbourne, Australia. Her research interests include investigations of innovative teaching methods, the development of graduate attributes, and information technology curricula design and Grace has published in these areas. 


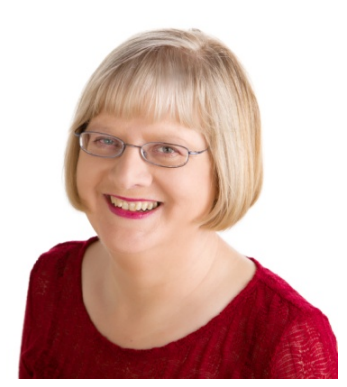

Anne Venables formerly lectured in Computer Science and Information Technology at Victoria University, Melbourne, Australia. She has research and teaching interests in innovations in computing education and the application of intelligent systems in biological systems. 